\title{
Changing TACTICS in intermediate HCC: TACE plus sorafenib
}

\author{
Pompilia Radu (D) , 1 Jean-François Dufour (D) 1,2
}

Hepatocellular carcinoma (HCC) represents a serious health problem, mainly due to the high cancer-related mortality. Transarterial chemoembolisation (TACE) is currently used as the first-line treatment for intermediate-stage HCC (Barcelona Clinic Liver Cancer (BCLC) stage B), despite the fact that this stage comprises patients with a wide range of liver function, variable tumour number and size. ${ }^{1-4}$ In clinical practice, only $50 \%-60 \%$ of patients with BCLC stage B benefit from TACE, so TACE is usually repeated to achieve maximum

\footnotetext{
${ }^{1}$ University Clinic for Visceral Surgery and Medicine, University of Bern, Inselspital, Bern, Switzerland ${ }^{2}$ Hepatology, Department of Clinical Research, University of Bern, Bern, Switzerland
}

Correspondence to Professor Jean-François Dufour, Hepatology, Department of Clinical Research, University of Bern, Bern 3010, Switzerland;

jean-francois.dufour@dbmr.unibe.ch tumour recession. The main factors that impact the effectiveness of TACE include the worsening of both the liver function and recurrence rate. The latter is the result of the angiogenic response triggered by TACEinduced hypoxia, which stimulates residual tumour growth. ${ }^{5}$ This has led to the concept that combining TACE with an antiangiogenic treatment such as sorafenib will offer better tumour control. ${ }^{6}$ During the last decade, this hypothesis was tested in several trials, but the results were inconsistent. ${ }^{7-10}$ According to a recent meta-analysis the combination of TACE plus sorafenib for unresectable HCC was superior in terms of time to progression but not in overall survival (OS). ${ }^{11}$

In Gut, a new trial combining TACE with sorafenib, the TACTICS trial, is published. ${ }^{12}$ The authors report that in patients with BCLC stage $\mathrm{B}$, the progression-free survival
(PFS), which was 13 months with TACE alone, reached 25 months with the addition of sorafenib to TACE. Similarly, the time to untreatable (unTACEable) progression increased significantly from 21 to 27 months. No significant differences in adverse events between the two treatment arms were observed. This trial stands out for being clearly positive with longer time to reach endpoints than those in previous trials (table 1).

Several aspects of the TACTICS trial have to be discussed. This trial used novel TACE progression criteria, according to which PFS was defined as the time to either unTACEable progression or death. Currently, the most commonly used evaluation radiological criteria of response to TACE are based on the measurement either of the tumour as a whole (Response Evaluation Criteria in Solid Tumors V.1.1) or of its viable portion (modified Response Evaluation Criteria in Solid Tumors), without taking into consideration the patterns of HCC progression. ${ }^{13}$ In the TACTICS trial, the authors evaluated the treatment based on the Response Evaluation Criteria in 
Table 1 TACE plus sorafenib trials for BCLC stage B

\begin{tabular}{|c|c|c|c|c|c|c|}
\hline \multicolumn{2}{|l|}{ Authors } & Kudo et $a^{7}$ & Park et $a l^{8}$ & Lencioni et $a l^{9}$ & Meyer et al ${ }^{10}$ & Kudo et al12 \\
\hline \multicolumn{2}{|l|}{ Trial } & Ph3 post-TACE & Ph2 TACE and sorafenib & Ph2 SPACE & Ph3 TACE-2 & Ph2 TACTICS \\
\hline \multicolumn{2}{|c|}{ Population randomised to sorafenib+TACE } & $\begin{array}{l}196 \text { patients, Japan, } \\
\text { and } 33 \text { patients, South } \\
\text { Korea }\end{array}$ & $\begin{array}{l}50 \text { patients, South } \\
\text { Korea }\end{array}$ & $\begin{array}{l}154 \text { of which } 59 \\
\text { were from Asia (not } \\
\text { including Japan) }\end{array}$ & 157 patients, UK & 80 patients, Japan \\
\hline \multicolumn{2}{|l|}{ Cirrhosis, yes } & $312(69.4 \%)$ & NA & $139(90.3 \%)$ & $129(82 \%)$ & NA \\
\hline \multicolumn{2}{|l|}{ Child Pugh A5, n \% } & NA & NA & $98(63.6 \%)$ & $106(68 \%)$ & $64(80.0 \%)$ \\
\hline \multicolumn{2}{|l|}{ Tumour burden } & $\begin{array}{l}\leq 7 \mathrm{~cm} \\
\leq 10 \text { lesions }\end{array}$ & $\mathrm{BCLC}$ stages $\mathrm{B}$ and $\mathrm{C}$ & $\begin{array}{l}\leq 7 \mathrm{~cm} \\
\leq 10 \text { tumours }\end{array}$ & $\begin{array}{l}\text { Unresectable, } \\
\text { multinodular not } \\
\text { amenable to resection or } \\
\text { transplantation }\end{array}$ & $\begin{array}{l}\leq 10 \mathrm{~cm} \\
\leq 10 \text { tumours }\end{array}$ \\
\hline \multicolumn{2}{|l|}{ Progression criteria } & RECICL 2004 & mRECIST & mRECIST & RECIST 1.1 & $\begin{array}{l}\text { UnTACEable progression/ } \\
\text { TACE failure } \\
\text { A new lesion was not } \\
\text { considered progressive } \\
\text { disease. }\end{array}$ \\
\hline \multirow[t]{2}{*}{ Overall survival (months) } & Combined treatment & 29.7 & NA & NR & 20.7 & NA \\
\hline & TACE alone & NA & NA & NR & 19.6 & NA \\
\hline \multirow[t]{2}{*}{ PFS (months) } & Combined treatment & NA & 7.1 & NA & 7.8 & 25.2 \\
\hline & TACE alone arm & NA & NA & NA & 7.7 & 13.5 \\
\hline \multirow[t]{2}{*}{ TTP (months) } & Combined treatment & 5.4 & 7.1 & 5.6 & 10.7 & 26.7 \\
\hline & TACE alone & 3.7 & NA & 5.5 & 10.5 & 16.4 \\
\hline \multirow[t]{2}{*}{ TTUP (months) } & Combined treatment & NA & NA & 3.1 & NA & 26.7 \\
\hline & TACE alone & NA & NA & 7.3 & NA & 20.6 \\
\hline \multicolumn{2}{|c|}{ Median daily sorafenib dose /day (mg) } & 386 & 600 & 566 & 660 & 355.2 \\
\hline \multicolumn{2}{|c|}{ The timing of pre-TACE/post-TACE sorafenib } & $\begin{array}{l}\text { Sorafenib was given } \\
1-3 \text { months after TACE } \\
\text { until progression. }\end{array}$ & $\begin{array}{l}\text { Sorafenib was given } \\
3 \text { days after TACE and } \\
\text { was administered for } \\
\text { up to } 24 \text { weeks. }\end{array}$ & $\begin{array}{l}\text { Sorafenib was started } \\
3-7 \text { days before DEB- } \\
\text { TACE, continuously } \\
\text { until progression. }\end{array}$ & $\begin{array}{l}\text { Sorafenib was started } \\
2-5 \text { weeks prior to DEB- } \\
\text { TACE continuously until } \\
\text { progression. }\end{array}$ & $\begin{array}{l}\text { Sorafenib was started } 2-3 \\
\text { weeks prior to first TACE, } \\
\text { discontinued for } 2 \text { days } \\
\text { before and } 2 \text { days after each } \\
\text { TACE session. }\end{array}$ \\
\hline \multicolumn{2}{|l|}{ TACE type and approach } & c TACE on demand & c TACE on demand & DEB-TACE scheduled & DEB-TACE on demand & c TACE on demand \\
\hline \multirow[t]{2}{*}{$\begin{array}{l}\text { Median durations of } \\
\text { treatment }\end{array}$} & $\begin{array}{l}\text { Combined treatment arm } \\
\text { (weeks on Sorafenib) }\end{array}$ & 17 & 5.1 & 21 & 3.9 & 38.7 \\
\hline & TACE alone arm (weeks) & 20 & NA & 27 & 5.3 & NA \\
\hline
\end{tabular}

BCLC, Barcelona Clinic Liver Cancer; DEB-TACE, transcatheter arterial embolisation with doxorubicin-eluting beads; mRECIST, modified Response Evaluation Criteria in Solid Tumors; NA, not available; NR, not reached; PFS, progression-free survival; RECICL, Response Evaluation Criteria in Cancer of the Liver; RECIST V.1.1, Response Evaluation Criteria in Solid Tumors V.1.1; C TACE, conventional transcatheter arterial embolisation; TACE, transcatheter arterial embolisation; TTP, time to progression; TTUP, time to unTACEable progression.

Cancer of the Liver (RECICL), according to which new intrahepatic lesions were no longer considered as progressive disease (PD). The PFS was defined as the time from randomisation to PD or death from any cause, and they define progression as untreatable (UnTACEable) progression, caused by the inability of a patient to further receive or benefit from TACE for reasons that included intrahepatic tumour progression (25\% increase vs baseline) according to RECICL, the detection of extrahepatic spread, vascular invasion or transient deterioration of liver function to Child- Pugh C after TACE.

The timing of sorafenib administration relative to TACE is important and differs among various studies. Several approaches have been tested for the timing of sorafenib initiation: (1) sequential administration, (2) the interrupted administration and (3) the continuous administration. ${ }^{14}$ The sequential approach involves treating patients with TACE, then initiating the sorafenib treatment (as an adjuvant therapy) once the TACE sessions have been completed. ${ }^{7}{ }^{8}$ The interrupted approach involves placing patients on treatment with sorafenib between the TACE sessions and pausing sorafenib during TACE to avoid possible adverse events. ${ }^{9} 10$ In the continuous approach, patients are prescribed sorafenib without interruption before, during and after TACE. Although the first two approaches might be superior in reducing complications, the third approach has the benefit of potentially eliminating the angiogenic response after TACE-induced hypoxia and may therefore prevent tumour growth after TACE. ${ }^{15}$ The feasibility of this approach was demonstrated in an initial phase I trial that assessed sorafenib given continuously and that began 7 days before TACE. ${ }^{16}$ In the TACTICS trial, patients included in the TACE plus sorafenib arm started sorafenib 2-3 weeks before TACE, at a dose of $400 \mathrm{mg}$ once daily. This approach aimed to normalise the tumour vasculature, improve TACE effectiveness and suppress the cascade of proangiogenetic signalling pathways triggered by TACE-induced hypoxia. In the TACTICS trial, TACE was administered 'on demand' at the growth of the viable lesions, whereas in the phase 2SPACE trial, the TACE sessions were scheduled. ${ }^{9}$

The population enrolled in the TACTICS trial differs significantly from the patient population enrolled in previous trials combining TACE with sorafenib. In the TACTICS trial, $80 \%$ of patients were classified as having Child-Pugh A5 compared with $60 \%-68 \%$ in previous trials. ${ }^{7-10}$ Not surprisingly, patients with a less advanced Child-Pugh stage tend to have a longer OS when treated with sorafenib. ${ }^{15}$ Another possible difference in the patient population is the percentage of non-cirrhotic patients. In previous trials, the cohorts comprised up to $80 \%$ of cirrhotic patients, while this proportion was not stated in the TACTICS trial.

These specificities in the TACTICS trial design resulted in a longer sorafenib treatment length (38 weeks) compared 
with previous trials (17-21 weeks). As BCLC stage B comprises a heterogeneous patient population, careful patient selection is essential. In this setting, several questions arise: (1) What is the benefit of adding sorafenib to TACE not only in terms of disease control but also in terms of quality of life and costs? (2) Which patients would benefit the most from the combination TACE and sorafenib (Asian/ non-Asian, cirrhotic/non cirrhotic)? (3) Which criteria are the most appropriate for evaluating therapeutic response? The answers to these questions are crucial in order to define the target population and to design the optimal protocol. The study by Kudo et al highlights the need to optimise treatment for patients with BCLC stage B. $^{12}$ In order to achieve this, redefining the criteria for both patient selection and treatment evaluation may be required. Until new trials for BCLC stage $\mathrm{B}$ confirm the results obtained by Kudo et al, it remains a matter of debate whether the combination of TACE plus sorafenib is a suitable choice of treatment for all patients with intermediate HCC or whether it should be reserved only for a specific group. Future studies that compare TACE plus sorafenib versus sorafenib alone in BCLC stage B may further improve our understanding of the real benefit of adding sorafenib to TACE.

Twitter Jean-François Dufour @dufour_jf

Contributors PR and J-FD wrote together this commentary.

Funding The authors have not declared a specific grant for this research from any funding agency in the public, commercial or not-for-profit sectors.

Competing interests J-FD: advisory committees: Bayer, BMS, Falk, Genfit, Genkyotex, Gilead Science, HepaRegenix, Intercept, Eli Lilly, Merck, Novartis; Speaking and teaching: Bayer, Bristol-Myers Squibb, Intercept, Genfit, Gilead Science and Novartis.

Patient and public involvement

statement Patients and/or the public were not involved in the design, or conduct, or reporting, or dissemination plans of this research.

Patient consent for publication Not required. Provenance and peer review Commissioned; internally peer reviewed.

\section{(2) \\ OPEN ACCESS}

Open access This is an open access article distributed in accordance with the Creative Commons Attribution Non Commercial (CC BY-NC 4.0) license, which permits others to distribute, remix, adapt, build upon this work non-commercially, and license their derivative works on different terms, provided the original work is properly cited, appropriate credit is given, any changes made indicated, and the use is non-commercial. See: http:// creativecommons.org/licenses/by-nc/4.0/.

(c) Author(s) (or their employer(s)) 2020. Re-use permitted under CC BY-NC. No commercial re-use. See rights and permissions. Published by BMJ.

\section{A Check for updates}

To cite Radu P, Dufour J-F. Gut 2020;69:1374-1376.

Received 16 January 2020

Revised 24 February 2020

Accepted 24 February 2020

Published Online First 13 March 2020

\section{(D) Linked}

- http://dx.doi.org/10.1136/gutjnl-2019-318934

Gut 2020;69:1374-1376.

doi:10.1136/gutjnl-2020-320692

\section{ORCID iDs}

Pompilia Radu http://orcid.org/0000-0001-7208-1477 Jean-François Dufour http://orcid.org/0000-0002-80621346

\section{REFERENCES}

1 Marrero JA, Kulik LM, Sirlin CB, et al. Diagnosis, staging, and management of hepatocellular carcinoma: 2018 practice guidance by the American association for the study of liver diseases. Hepatology 2018;68:723-50.

2 Omata M, Cheng A-L, Kokudo N, et al. Asia-Pacific clinical practice guidelines on the management of hepatocellular carcinoma: a 2017 update. Hepatol Int 2017:11:317-70.
3 Korean Liver Cancer Association, National Cancer Center. 2018 Korean liver cancer Association-National cancer center Korea practice guidelines for the management of hepatocellular carcinoma. Gut Liver 2019;13:227-99

4 Bolondi L, Burroughs A, Dufour J-F, et al. Heterogeneity of patients with intermediate (BCLC B) hepatocellular carcinoma: proposal for a subclassification to facilitate treatment decisions. Semin Liver Dis 2012;32:348-59.

5 Lencioni R. Loco-Regional treatment of hepatocellular carcinoma. Hepatology 2010;52:762-73.

6 Dufour J-F, Johnson P. Liver cancer: from molecular pathogenesis to new therapies: summary of the EASL single topic conference. J Hepatol 2010;52:296-304.

7 Kudo M, Imanaka K, Chida N, et al. Phase III study of sorafenib after transarterial chemoembolisation in Japanese and Korean patients with unresectable hepatocellular carcinoma. Eur J Cancer 2011:47:2117-27.

8 Park J-W, Koh YH, Kim HB, et al. Phase II study of concurrent transarterial chemoembolization and sorafenib in patients with unresectable hepatocellular carcinoma. J Hepatol 2012:56:1336-42.

9 Lencioni R, Llovet JM, Han G, et al. Sorafenib or placebo plus TACE with doxorubicin-eluting beads for intermediate stage HCC: the space trial. $J$ Hepatol 2016;64:1090-8.

10 Meyer T, Fox R, Ma YT, et al. Sorafenib in combination with transarterial chemoembolisation in patients with unresectable hepatocellular carcinoma (TACE 2): a randomised placebo-controlled, doubleblind, phase 3 trial. Lancet Gastroenterol Hepatol 2017;2:565-75.

11 Li L, Zhao W, Wang M, et al. Transarterial chemoembolization plus sorafenib for the management of unresectable hepatocellular carcinoma: a systematic review and meta-analysis. BMC Gastroenterol 2018;18:138.

12 Kudo M, Ueshima K, Ikeda M, et al. Randomised, multicentre prospective trial of transarterial chemoembolisation (TACE) plus sorafenib as compared with TACE alone in patients with hepatocellular carcinoma: TACTICS trial 2019.

13 Tovoli F, Renzulli M, Granito A, et al. Radiologic criteria of response to systemic treatments for hepatocellular carcinoma. Hepat Oncol 2017;4:129-37.

14 Strebel BM, Dufour J-F. Combined approach to hepatocellular carcinoma: a new treatment concept for nonresectable disease. Expert Rev Anticancer Ther 2008;8:1743-9.

15 Ziogas IA, Tsoulfas G. Evolving role of sorafenib in the management of hepatocellular carcinoma. World J Clin Oncol 2017:8:203-13.

16 Dufour J-F, Hoppe H, Heim MH, et al. Continuous administration of sorafenib in combination with transarterial chemoembolization in patients with hepatocellular carcinoma: results of a phase I study. Oncologist 2010;15:1198-204. 